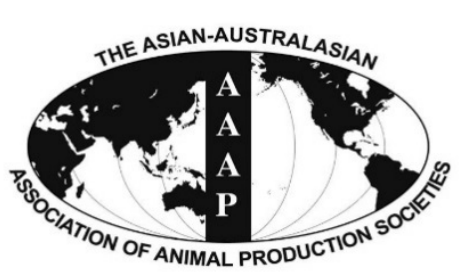

Open Access

Asian Australas. J. Anim. Sci.

Vol. 29, No. 8 : 1173-1180 August 2016

http://dx.doi.org/10.5713/ajas.15.0738

www.ajas.info

pISSN 1011-2367 elSSN 1976-5517

\title{
Beneficial Effects of Traditional Seasonings on Quality Characteristics of Fermented Sausages
}

\author{
Pil-Nam Seong, Hyun-Woo Seo, Sun-Moon Kang, Yoon-Seok Kim, Soo-Hyun Cho, \\ Jin-Hyoung Kim, and Van-Ba Hoa* \\ Animal Products and Processing Division, National Institute of Animal Science, \\ Wanju 565-851, Korea
}

\begin{abstract}
Though traditional seasonings are widely used in many dishes, however, no attention has been paid to the investigation of their effects on quality characteristics of food products. The present investigation was undertaken to study the effects of incorporating several traditional seasonings including doenjang (fermented soybean paste), gochu-jang (red pepper paste), fresh medium-hot, and hot peppers, and fresh garlic on the lipid oxidation, cholesterol content and sensory characteristics of fermented sausages. Six fermented sausage treatments $(5$ with $1 \%(\mathrm{w} / \mathrm{w})$ each test seasoning and 1 without added test seasoning (control) were prepared. The addition of seasonings generally had beneficial effects on the improvement of fermented sausage's quality however the effects differed depending on the each type of seasonings added. Significant lower $\mathrm{pH}$ values were found in all fermented sausages made with the seasonings while, lower levels of lipid oxidation were found in the treatments with hot peppers and garlic as compared with the control ( $\mathrm{p}<0.05$ ). The treatment with seasonings did not cause color or texture defects in the products whereas the sausages made with gochu-jang had significantly higher Commission International de l'Eclairagea* (redness) value in comparison with the control. Noticeably, incorporating doenjang, medium-hot peppers, hot peppers and garlic resulted in reduction of 26.50, 32.54, 47.04, and $48.54 \mathrm{mg}$ cholesterol/100 $\mathrm{g}$ samples, respectively $(\mathrm{p}<0.05)$. Higher scores for the sensory traits such as aroma, taste, color and acceptability were also given for the sausages made with seasonings. The current work demonstrates that the test seasonings represent potentially natural ingredients to be used for producing healthier fermented sausages. (Key Words: Fermented Sausage, Traditional Seasonings, Lipid Oxidation, Cholesterol, Sensory)
\end{abstract}

\section{INTRODUCTION}

Fermented sausages are generally manufactured with about $60 \%$ to $80 \%$ raw meat, $20 \%$ to $40 \%$ fat and along with additives and spices etc. (Nassua et al., 2003; Kurćubić et al., 2014). The fermented sausages are a rich source of high biological value proteins, energy and minerals. Moreover, the products are generally produced without any heat treatment throughout the process of fermentation, ripening and drying, which enables nutritional values to remain unchanged. However, the products also have some negative aspects such as unfavorable polyunsaturated/

\footnotetext{
* Corresponding Author: Van-Ba Hoa. Tel: +82-63-238-7358, Fax: +82-63-238-7397, E-mail: hoavanba@jbnu.ac.kr Submitted Sept. 3, 2015; Revised Oct. 25, 2015; Accepted Nov. 24, 2015
}

saturated fatty acid ratio and an especially high cholesterol level due to the high added fat level (Muguerza et al., 2001). Besides, the products are highly susceptible to lipid oxidation which generates toxic molecules with possible hazard for human health as well as reducing shelf-life stability of the product (Zanardi et al., 2004). Therefore, the control of lipid oxidation and reducing the cholesterol content are necessary to improve the shelf-life stability and health effect of fermented sausages. Despite lipid oxidation in meat products being controlled or minimized, by the addition of commercial synthetic antioxidants, the available synthetic antioxidants (e.g., butylated hydroxyanisole and butylated hydroxytoluene) have been suspected to cause toxicity problems that negatively affect consumer's health. Therefore, these compounds have had their use restricted in foods (Botterweck et al., 2000). Consumers are increasingly 
aware of the importance of their food choices in health maintenance and disease prevention, therefore, a new trend to substitute these synthetic additives with natural functional ingredients has received serious attention from consumers and meat processors (Nassua et al., 2003; Kurćubić et al., 2014; Chaves-López et al., 2015). In addition, the incorporation of natural additives into the conventional processing formulations makes the meat products not only healthier but also improves sensory quality (Ozvural and Vural, 2011; Seong et al., 2015).

Doenjang, a soybean fermented product, has long been used as a healthy food and seasoning in Korea and this kind of product is also widely used in other countries such as China and Japan etc. The doenjang is a rich source of protein, carbohydrates, unsaturated fatty acids and soluble fiber, and more importantly it contains a significant level of bioactive compounds which exert a potent biological activity such as antioxidant, antimicrobial, anticancer and anti-obesity effects (Kim et al., 2005; Cha et al., 2014; Shukla et al., 2014). Like the doenjang, gochu-jang, a kind of red pepper paste made from dried pepper powder, water, salt, fermented soybean and sweet rice powder, is also commonly used as a seasoning in many dishes in Korea (Kwon et al., 2015). Besides, the other plant-sourced seasonings such as fresh chili peppers and garlic are also widely used not only for their ability to enhance the typical flavor of dishes or food products but also for their beneficial effects on health such as reducing cholesterol level in blood and cardiovascular risk (Hermansen et al., 2003).

In previous studies, authors have demonstrated that the addition of natural ingredients such as mushroom powder could significantly improve the sensory quality (e.g., taste, flavor and overall acceptability) of meat products such as frankfurters (Seong et al., 2015). While the traditional seasonings from natural sources like doenjang, gochu-jang, fresh garlic and chili peppers are abundant, inexpensive and widely used for multi-purposes as mentioned above, no attention has been paid to the effects of their addition on the quality of meat products. Therefore, the objective of the present study was to assess the impacts of incorporation of some traditional seasonings on the technological quality characteristics, cholesterol content and sensory perception of fermented sausages.

\section{MATERIALS AND METHODS}

\section{Materials}

Pork ham and back-fat were obtained from a local slaughterhouse (Suwon, Korea) $24 \mathrm{~h}$ after slaughter. Korean traditional seasonings including doenjang and gochu-jang, and natural seasonings such as fresh green medium-hot peppers, green hot peppers and fresh garlic cloves were purchased from a local market in Suwon, South Korea. The other ingredients used were sodium nitrite and sodium nitrate (Sigma Chemical Co. St. Louis, MO, USA), polyphosphate and sodium ascorbate (Shinyo Pure Chemicals Co. Osaka, Japan), sodium chloride (Hanju Co. Ulsan, Korea), sugar and black pepper (Beksul Food Co. Seoul, Korea).

\section{Fermented sausage formulation and processing}

Fresh peppers (both medium-hot and hot types) and garlic cloves were washed to remove any impurities, left to drain the water, cut and then ground separately using a blender (HMF 3160S, Hanil Electric, Co, Seoul, Korea). The initial $\mathrm{pH}$ values of goenjang, gochu-jang, ground medium-hot peppers (GMP), ground hot peppers (GHP) and ground garlic (GG) were 5.70, 5.45, 5.65, 5.63, and 5.80 , respectively.

Six different treatments of dry fermented sausages (20 $\mathrm{kg}$ each) were prepared in the present study. All sausage treatments $(\mathrm{T})$ were formulated with $80 \%$ pork ham, $20 \%$ pork backfat, $2 \%$ sodium chloride, $1.5 \%$ sugar, $0.2 \%$ black pepper, $0.2 \%$ polyphosphate, $0.03 \%$ sodium ascorbate, $0.01 \%$ sodium nitrite and $0.005 \%$ sodium nitrate. Besides, $1 \%(\mathrm{w} / \mathrm{w})$ of each test seasonings such as doanjang, gochujang, GMP, GHP, and GG was added to the T1, T2, T3, T4, and T5, respectively. The batch made without the added test seasonings served as the control. The processing procedure of fermented sausages was performed as follows: The refrigerated meat ( $48 \mathrm{~h}$ after slaughter) was first trimmed of all connective tissue and visible fats and then cut into small pieces. The trimmed meat and pork back-fat were chopped through a $0.5 \mathrm{~cm}$ plate using a silent chopper (Model 7548, Biro MFG. Co, Marblehead, OH, USA). The chopped meat was then mixed with all of the ingredients (except for the test seasonings) and left in a chilling room for overnight. The following day, for each treatment, the chopped meat and fat were placed in a meat tumbler and mixer (model CE93, RUHLE GMBH, Grafenhausen, Germany) and then the test seasoning was also added to the corresponding treatment and mixed for further $15 \mathrm{~min}$ at $4^{\circ} \mathrm{C}$. After mixing, the meat batters were immediately stuffed into $110-\mathrm{mm}$ diameter collagen casings (Naturin Viscofan Co, Navarra, Spain) using a vacuum stuffer (Model VF610, Handtmann Co, Biberach, Germany), resulting in sausages of ca. $1.5 \mathrm{~kg}$. The filled sausages were then hung vertically on metal rods, set on the cart and transferred to an air-conditioned chamber for fermenting, ripening and drying. Temperature and relative humidity $(\mathrm{RH})$ conditions in the air-conditioned chamber during fermentation, ripening and drying were set as follows: $15^{\circ} \mathrm{C} / 90 \%$ to $100 \% \mathrm{RH}$ for $18 \mathrm{~h}, 22^{\circ} \mathrm{C} / 90 \% \mathrm{RH}$ for $48 \mathrm{~h}, 14^{\circ} \mathrm{C}$ to $15^{\circ} \mathrm{C} / 80 \%$ to $90 \% \mathrm{RH}$ for 10 days, $14^{\circ} \mathrm{C} / 75 \% \mathrm{RH}$ for 28 days. At the end of the ripening/ 
drying (42 days), the fermented sausages were collected and stored at $4{ }^{\circ} \mathrm{C}$ until use.

For the sample preparation, the outer casings were removed, and each fermented sausage was cut into subsample sizes depending on type of analysis. The samples used for analyses of proximate composition, $\mathrm{pH}$, lipid oxidation and cholesterol and sodium were ground with a meat blender, vacuum-packed in polyethylene bags and stored at $-20^{\circ} \mathrm{C}$ until analysis, while the samples for the sensory evaluation was used on the same sample preparation day.

\section{Proximate composition}

Moisture, fat and protein contents were analyzed using the method of the Association of Official Analytical Chemists (AOAC, 2000). Particularly, the moisture and fat contents were determined by using a Food Scan Lab 78810 (Foss Tecator Co., Ltd., Hillerod, Denmark); while, the nitrogen content was determined by using a nitrogen analyzer (Rapid N cube, Elementar, Hanau, Germany) and then converted into protein content using the $\mathrm{N} \times 6.25$ equation $(\mathrm{N}=$ nitrogen content obtained from the samples, and $6.25=$ conversion factor). To determine calories, the sample was homogenized in a blender then the homogenate was used for measurement of calorie content with a calorimeter (model 6400, Parr instrument, Moline, IL, USA). Calories were expressed as $\mathrm{kcal} / 100 \mathrm{~g}$ of the sample.

\section{pH and water activity $\left(a_{w}\right)$}

The $\mathrm{pH}$ values of samples were determined in triplicates using a pH meter (Model 340, Mettler-Toledo $\mathrm{GmbH}$, Schwerzenbach, Switzerland) that was calibrated with 3 different standard $\mathrm{pH}$ solutions (4.0, 7.0, and 9.25). The $\mathrm{pH}$ was measured after homogenizing $3 \mathrm{~g}$ of each sample with $27 \mathrm{~mL}$ of distilled water for $30 \mathrm{~s}$ using a homogenizer.

Water activity $\left(a_{\mathrm{w}}\right)$ of the fermented sausages was determined at $25^{\circ} \mathrm{C}$ with a measuring instrument; model AW SPRINT-TH 300 (Novasina Co, Lachen, Switzerland). Calibration was done by using several saturated solutions of known $\mathrm{a}_{\mathrm{w}}$.

\section{Color measurement}

Color was determined at 3 defined areas on the cut surface of each sample using a Minolta Chroma Meter CR400 (Minolta Camera Co., Ltd., Osaka, Japan) that was standardized with a white plate $(\mathrm{Y}=86.3, \mathrm{X}=0.3165$, and $\mathrm{y}=0.3242$ ). Special care was taken to avoid scanning areas of fat in the sample. Color was expressed according to the Commission International de l'Eclairage (CIE) system and reported as CIE L* (lightness), CIE a* (redness), CIE b* (yellowness), chroma and hue angle $\left(\mathrm{h}^{\circ}\right)$. In which the chroma and hue angle were calculated as $\left(a^{* 2}+b^{* 2}\right)^{0.5}$ and $\tan ^{-1}\left(b^{*} / a^{*}\right)$, respectively.

\section{Texture analysis}

The texture properties were analyzed using a puncture probe $(7 \mathrm{~mm}$ diameter) attached to a texture Analyzer (Model 4465, Instron Corp, High Wycombe, UK). For texture analysis, the samples from each treatment were cut into $2.5 \mathrm{~cm}$ long pieces; the cube was axially compressed twice until at each time reaching $80 \%$ of its initial height. The speed of load cell was set at $120 \mathrm{~mm} / \mathrm{min}$ and the following parameters were calculated: hardness $(\mathrm{kg})$, cohesiveness $(\mathrm{kg} \times \mathrm{mm})$, gumminess $(\mathrm{kg})$ and chewiness $(\mathrm{kg} \times \mathrm{mm})$.

\section{Lipid oxidation}

The content of thiobarbituric acid reactive substances (TBARS) was determined to evaluate the lipid oxidation level in samples between the treatments, using the method of Pikul et al. (1987). Briefly, each sample (5 g) with 17.5 $\mathrm{mL}$ of $4 \%$ perchloric acid and $0.5 \mathrm{~mL}$ of $7.5 \%$ butylated hydroxyansole in ethanol was homogenized at $13,000 \times \mathrm{rpm}$ for $20 \mathrm{~s}$ using a homogenizer (Polytron MR-2100, Kinematica AG, Lucerne, Switzerland). The volume of the homogenate was adjusted to $25 \mathrm{~mL}$ with $4 \%$ perchloric acid solution and then filtered through No. 1 Whatman filter paper. The filtrate $(5 \mathrm{~mL}$ each) was transferred to separate test tubes and mixed with $5 \mathrm{~mL}$ of $0.02 \mathrm{M}$ thiobarbituric acid solution, the mixtures were then heated at $80^{\circ} \mathrm{C}$ for $1 \mathrm{~h}$ in a water-bath. After being cooled with cold water, about $1.5 \mathrm{~mL}$ of each sample was taken and the absorbance was measured at $532 \mathrm{~nm}$ using an UV-visible spectrophotometer (Proteome Lab Du-800, Beckman Coulter, Inc., Fullerton, CA, USA). TBARS concentrations were calculated by multiplying the absorbance by a constant coefficient of 5.5 which was obtained from standard curves and known dilutions $(0.1$ to $0.8 \mu \mathrm{M})$ of $1,1,3,3$ tetramethoxypropane (Aldrich, Louis, MA, USA). The TBARS value was expressed as $\mathrm{mg}$ malonaldehyde $/ \mathrm{kg}$ of sample. Three repetitions were applied for each sample in each treatment.

\section{Cholesterol, monosaccharide, and sodium compositions}

The cholesterol, monosaccharide and sodium contents in the fermented sausages were determined using the methods standardized by the Ministry of Food and Drug Safety of Korea (MFDA, 2014).

\section{Sensory evaluation}

Sensory evaluation was performed using a panel consisting of 12 assessors. The panelists, with average age of 35 years, were the staff of the department of animal products processing and utilization, National Institute of Animal Science, Korea, and were chosen on the basis of 
previous experience in sensory evaluation of meat products. Briefly, each sausage sample was cut into $0.3 \mathrm{~cm}$ thick pieces, placed onto dishes and coded with random numbers. The panelists were seated in private seats under fluorescent lighting and were served with the sensory samples in a random manner. Five major sensory traits including aroma, texture, color, taste and overall acceptability were used and the samples were then evaluated for the aforementioned traits using a 7-point scale $(1$ point $=$ extremely undesirable, 7 point $=$ extremely desirable $)$ as described by Meilgaard et al. (1991). The panelists were asked to refresh their mouth with drinking distilled water and salt-free crackers between samples. All sensory sessions were carried out in the sensory panel booth room equipped with white lighting at a constant temperature of about $20^{\circ} \mathrm{C}$.

\section{Statistic analysis}

The data were subjected to statistical analysis using the Statistic Analysis System (SAS, 2007) package (SAS Institute, Cary, NC, USA). All data were analyzed by the general linear model procedure considering treatment the main effect. Means were compared using Duncan's Multiple Range Test, with a significance of $\mathrm{p}<0.05$.

\section{RESULTS AND DISCUSSION}

\section{Effect on proximate composition}

The incorporation of seasonings into the processing formulations had minor effects on the proximate compositions (Table 1). For moisture, no differences were found between the control and treatments $(p>0.05)$, however, when comparing the moisture contents among the treatments, the samples made with GHP (T4) had a significantly higher level than those made with doenjang $(p<0.05)$. Moisture content is one of the important waterrelated criteria used to indicate the shelf-life stability of the dry cured meat products. The moisture contents ranging between the treatments from $34.90 \%$ to $38.36 \%$ in the present work were generally lower than the levels ( $41.3 \%$ to $54.7 \%$ ) in fermented sausages ripened for 21 days (Kim et al., 2014), but slightly higher than the levels $(29.32 \%$ to $33.93 \%$ ) in fermented sausages ripened for 25 days (Yim et al., 2015). This is probably due to the differences in the added level of fat, casing size and ripening conditions among the studies. The samples made with GHP (T4) had lower fat content $(26.38 \%)$ compared to those of the control as well as other remaining treatments $(p<0.05)$. The protein contents ranged between the treatments from $23.06 \%$ to $25.78 \%$, despite the addition of doenjang or gochu-ang resulting in approximately $1 \%$ protein increase, the statistically analytic results showed no differences between the control and these treatments ( $>>0.05)$. Comparing the protein contents between the treatments shows that the sausages made with gochu-jang (T2) and GHP (T4) had significantly higher levels compared to the ones made with GMP (T3) and GG (T5) $(\mathrm{p}<0.05)$. Regarding calories, the sausages made with gochu-jang (T2) had higher level compared to that of the control and other remaining treatments, probably due to the presence of sugar and sweet rice flour in this seasoning whereas, the lower energy found in sausages made with GHP (T4) could be due its lower fat content (Table 1).

\section{Effect on technological quality traits}

Some technological quality traits of the fermented sausages in different treatments are presented in Table 2. The $\mathrm{pH}$ values ranged between the treatments from 4.70 to 4.86 , in which the sausages made with either doenjang or gochu-jang and garlic had significantly lower values in comparison with the control, this could be due to higher level of acid lactic produced in these treated samples. The $\mathrm{pH}$ values in the treated samples in present study were generally lower than the values (4.98 to 5.33) reported for the ones made with addition of starter cultures (Corrall et al., 2014; Yim et al., 2015). It is well known that the shelf-life of meat products is affected by a number of factors including $\mathrm{pH}$ condition; the lower the $\mathrm{pH}$ the higher the acidity and most bacteria that contribute to food spoilage do not prosper in acidic conditions. Thus, these $\mathrm{pH}$ results could be considered high enough to ensure the safety of meat products (Papadima and Bloukas, 1999), and also suggests that the incorporation of these seasonings may partly enhance the shelf-life stability of fermented sausages.

Statistical analysis revealed that the water activity $\left(a_{w}\right)$ in all treatments was not significantly different from the control $(p>0.05)$, suggesting that the treatment did not affect

Table 1. Proximate compositions of fermented sausages as affected by the seasonings addition ${ }^{1}$

\begin{tabular}{|c|c|c|c|c|}
\hline Treatment & Moisture (\%) & Fat $(\%)$ & Calorie $(\mathrm{Kcal} / 100 \mathrm{~g})$ & Protein $(\%)$ \\
\hline Control (C) & $37.28 \pm 1.37^{\mathrm{ab}}$ & $27.38 \pm 0.65^{\mathrm{a}}$ & $409.26 \pm 9.37^{b}$ & $24.70 \pm 1.17^{\mathrm{abc}}$ \\
\hline 1\%doenjang (T1) & $34.90 \pm 0.13^{\mathrm{b}}$ & $28.58 \pm 0.47^{\mathrm{a}}$ & $415.96 \pm 8.01^{b}$ & $25.46 \pm 0.29^{\mathrm{ab}}$ \\
\hline 1\%gochu-jang (T2) & $36.82 \pm 0.33^{\mathrm{ab}}$ & $27.92 \pm 0.43^{\mathrm{a}}$ & $440.50 \pm 6.66^{\mathrm{a}}$ & $25.78 \pm 0.83^{\mathrm{a}}$ \\
\hline $1 \%$ ground medium-hot peppers (T3) & $37.33 \pm 0.35^{\mathrm{ab}}$ & $29.11 \pm 0.36^{\mathrm{a}}$ & $411.66 \pm 6.81^{b}$ & $23.06 \pm 0.77^{\mathrm{c}}$ \\
\hline $1 \%$ ground hot peppers $(\mathrm{T} 4)$ & $38.36 \pm 0.59^{\mathrm{a}}$ & $26.38 \pm 0.40^{\mathrm{b}}$ & $376.56 \pm 11.95^{\mathrm{c}}$ & $25.78 \pm 0.34^{\mathrm{a}}$ \\
\hline $1 \%$ ground garlic $(\mathrm{T} 5)$ & $37.35 \pm 1.81^{\mathrm{ab}}$ & $27.75 \pm 0.77^{\mathrm{a}}$ & $406.62 \pm 4.28^{\mathrm{b}}$ & $23.34 \pm 0.23^{\mathrm{bc}}$ \\
\hline
\end{tabular}

\footnotetext{
${ }^{1}$ Data are the means \pm standard deviation.

Values with different letters $\left({ }^{a-c}\right)$ in the same column differ significantly $(p<0.05)$
} 
Table 2. Technological quality traits and lipid oxidation of fermented sausages as affected by the seasonings addition ${ }^{1}$

\begin{tabular}{lcccc}
\hline Treatment & $\mathrm{pH}$ & $\begin{array}{c}\text { Water activity } \\
(\mathrm{aw})\end{array}$ & $\begin{array}{c}\text { Weight loss } \\
(\%)\end{array}$ & $\begin{array}{c}\text { TBARS } \\
(\mathrm{mg} \text { MDA/kg sample) }\end{array}$ \\
\hline Control (C) & $4.86 \pm 0.01^{\mathrm{a}}$ & $0.86 \pm 0.00^{\mathrm{ab}}$ & $36.94 \pm 0.14^{\mathrm{c}}$ & $1.53 \pm 0.2^{\mathrm{ab}}$ \\
$1 \%$ doenjang (T1) & $4.74 \pm 0.01^{\mathrm{b}}$ & $0.86 \pm 0.00^{\mathrm{b}}$ & $37.98 \pm 0.19^{\mathrm{b}}$ & $1.30 \pm 0.1^{\mathrm{bc}}$ \\
$1 \%$ gochu-jang (T2) & $4.70 \pm 0.02^{\mathrm{b}}$ & $0.86 \pm 0.00^{\mathrm{ab}}$ & $37.20 \pm 0.14^{\mathrm{c}}$ & $1.34 \pm 0.2^{\mathrm{bc}}$ \\
$1 \%$ ground medium-hot peppers (T3) & $4.75 \pm 0.01^{\mathrm{b}}$ & $0.87 \pm 0.00^{\mathrm{a}}$ & $37.03 \pm 0.21^{\mathrm{c}}$ & $1.70 \pm 0.2^{\mathrm{a}}$ \\
$1 \%$ ground hot peppers (T4) & $4.85 \pm 0.02^{\mathrm{a}}$ & $0.86 \pm 0.00^{\mathrm{a}}$ & $40.73 \pm 0.26^{\mathrm{a}}$ & $1.21 \pm 0.1^{\mathrm{c}}$ \\
$1 \%$ ground garlic (T5) & $4.73 \pm 0.02^{\mathrm{b}}$ & $0.87 \pm 0.00^{\mathrm{a}}$ & $35.36 \pm 0.41^{\mathrm{d}}$ & $1.22 \pm 0.1^{\mathrm{c}}$ \\
\hline
\end{tabular}

TBARS, thiobarbituric acid reactive substances; MDA, malonaldehyde.

${ }^{1}$ Data are the means \pm standard deviation.

Values with different letters $\left({ }^{a-d}\right)$ in the same column differ significantly $(p<0.05)$.

the rate of water activity reduction. However, comparison of the $a_{w}$ values in samples between the treatments shows that the treatment with doenjang had significantly $(\mathrm{p}<0.05)$ lower value compared to the other remaining treatments. It is well known that the shelf-life stability of food products usually increases with decreasing $\mathrm{a}_{\mathrm{w}}$, as a high $\mathrm{a}_{\mathrm{w}}$ (e.g., around 0.95) can form an ideal medium for bacterial growth (Frenandez-Salguero et al., 1993). The $a_{w}$ values in fermented sausages made with seasoning in the present study were lower than the values (0.906 to 0.916) in fermented sausages ripened for 61 days (Corral et al., 2014) but almost similar to the values (0.865) in samples ripened for 15 days (Zapenela et al., 1999). For weight loss, no differences occurred between the control and gochu-jang or GMP treatment $(\mathrm{p}>0.05)$, while the treatment with GHP had significantly higher while the treatment with garlic had lower loss levels compared to the control $(\mathrm{p}<0.05)$.

Regarding the lipid oxidation, it was observed that most treatments with the seasonings generally led to a reduction in TBARS content as compared to the control, however, the significant $(p<0.05)$ differences only were observed for the samples treated with GHP or garlic. The results indicate that the lipid oxidation was inhibited by the added GHP and garlic contents; this could be due to the actions of antioxidants present in these seasonings. Earlier workers have shown that garlic and hot peppers contain bioactive compounds such as; allyl disulfide, alliin and allicin and phenols that are powerful antioxidants (Materska and Perucka, 2005; Chung, 2006). For the cases of doenjang, and gochu-jang treatments, despite these seasonings alone have been proven to possess high antioxidant activity in vitro and in vivo studies (Kim et al., 2005; Shukla et al., 2014), the addition of these contents at level of $1 \%$ did not significantly reduce the lipid oxidation in the fermented sausages, perhaps due to the low added level. Therefore, further study using higher concentrations is needed to assess the antioxidant potential of these seasonings in fermented sausages.

\section{Effects on color}

Color attributes of fermented sausages as affected by the addition of various seasonings are presented in Table 3 . Regarding L* (lightness), all the treatments with seasonings did not affect the lightness of the products, except the treatment with GHP which showed lower $\mathrm{L}^{*}$-value in comparison to the control samples. Similarly, no differences in $\mathrm{a}^{*}$ (redness)-values occurred between the control samples and those with added doenjang or gochu-jang and GHP $(\mathrm{p}>0.05)$. However, the sausages produced with gochu-jang had significantly $(\mathrm{p}<0.05)$ higher $\mathrm{a}^{*}$-values compared with that of the control, probably resulting from the suppression of the product's natural color owing to the addition of gochu-jang. For the other remaining color traits such as $b^{*}$ (yellowness), chroma and hue angle, the values in most treatments were similar to that in the control samples, excepted for the treatment with gochu-jang which showed significantly $(p<0.05)$ higher values. Color is the single most important factor of meat products affecting the

Table 3. Color traits of fermented sausages as affected by the seasonings addition ${ }^{1}$

\begin{tabular}{lccccc}
\hline Treatment & CIE L* & CIE a* & CIE b* $^{*}$ & Chroma & Hue \\
\hline Control (C) & $54.34 \pm 0.57^{\mathrm{a}}$ & $12.12 \pm 0.30^{\mathrm{bc}}$ & $6.15 \pm 0.21^{\mathrm{b}}$ & $13.60 \pm 0.36^{\mathrm{b}}$ & $26.89 \pm 0.24^{\mathrm{d}}$ \\
$1 \%$ doenjang (T1) & $53.90 \pm 0.41^{\mathrm{a}}$ & $12.47 \pm 0.35^{\mathrm{ab}}$ & $6.07 \pm 0.14^{\mathrm{b}}$ & $13.88 \pm 0.37^{\mathrm{b}}$ & $25.99 \pm 0.26^{\mathrm{d}}$ \\
$1 \%$ gochu-jang (T2) & $53.92 \pm 0.87^{\mathrm{a}}$ & $13.51 \pm 0.73^{\mathrm{a}}$ & $10.09 \pm 0.61^{\mathrm{a}}$ & $16.87 \pm 0.94^{\mathrm{a}}$ & $36.67 \pm 0.46^{\mathrm{a}}$ \\
$1 \%$ ground medium-hot peppers (T3) & $54.13 \pm 0.36^{\mathrm{a}}$ & $10.95 \pm 0.22^{\mathrm{c}}$ & $6.96 \pm 0.11^{\mathrm{b}}$ & $13.00 \pm 0.24^{\mathrm{b}}$ & $32.60 \pm 0.12^{\mathrm{b}}$ \\
$1 \%$ ground hot peppers (T4) & $51.65 \pm 0.42^{\mathrm{b}}$ & $12.74 \pm 0.31^{\mathrm{ab}}$ & $6.24 \pm 0.10^{\mathrm{b}}$ & $14.19 \pm 0.31^{\mathrm{b}}$ & $26.11 \pm 0.36^{\mathrm{d}}$ \\
$1 \%$ ground garlic (T5) & $54.90 \pm 0.44^{\mathrm{a}}$ & $11.61 \pm 0.22^{\mathrm{bc}}$ & $6.48 \pm 0.12^{\mathrm{b}}$ & $13.31 \pm 0.15^{\mathrm{b}}$ & $29.23 \pm 0.86^{\mathrm{c}}$ \\
\hline
\end{tabular}

CIE, Commission International de l'Eclairage.

${ }^{1}$ Data are the means \pm standard deviation.

Values with different letters $\left({ }^{\mathrm{a}-\mathrm{d}}\right)$ in the same column differ significantly $(\mathrm{p}<0.05)$. 
Table 4. Texture profiles of fermented sausages as affected by adding traditional seasonings ${ }^{1}$

\begin{tabular}{|c|c|c|c|c|}
\hline Treatment & Hardness (kg) & Cohesiveness & Gumminess (kg) & Chewiness $(\mathrm{kg} \times \mathrm{mm})$ \\
\hline Control (C) & $1.83 \pm 0.19^{\mathrm{ab}}$ & $1.29 \pm 0.34$ & $2.42 \pm 0.77$ & $7.03 \pm 4.22$ \\
\hline $1 \%$ doenjang (T1) & $1.97 \pm 0.01^{\mathrm{a}}$ & $1.33 \pm 0.35$ & $2.62 \pm 0.71$ & $7.88 \pm 3.26$ \\
\hline 1\% gochu-jang (T2) & $1.71 \pm 0.06^{\mathrm{ab}}$ & $1.68 \pm 0.53$ & $2.90 \pm 0.94$ & $10.16 \pm 4.79$ \\
\hline $1 \%$ ground medium-hot peppers (T3) & $1.33 \pm 0.06^{\mathrm{c}}$ & $0.72 \pm 0.20$ & $0.97 \pm 0.29$ & $1.11 \pm 0.63$ \\
\hline $1 \%$ ground hot peppers $(\mathrm{T} 4)$ & $1.85 \pm 0.04^{\mathrm{ab}}$ & $1.74 \pm 0.22$ & $3.24 \pm 0.49$ & $11.01 \pm 3.33$ \\
\hline $1 \%$ ground garlic $(\mathrm{T} 5)$ & $1.60 \pm 0.07^{\mathrm{bc}}$ & $1.53 \pm 0.37$ & $2.46 \pm 0.62$ & $6.84 \pm 2.72$ \\
\hline
\end{tabular}

${ }^{1}$ Data are the means \pm standard deviation.

Values with different letters $\left.{ }^{(a-c}\right)$ in the same column differ significantly $(\mathrm{p}<0.05)$.

consumer purchasing decision, and nitrite has long been used to enhance the red color of these products (Honikel, 2008). However, the use of nitrite in meat product is also associated with health risk (Chow and Hong, 2002), researchers therefore have been attempting to reduce the added nitrite content in meat products by partially replacing it with natural additives (Deda et al., 2007). Thus, it appears that the addition of the seasonings did not cause color defects in the fermented sausages. Additionally, the incorporation of gochu-jang improved the red color of fermented sausages, suggesting that the addition of gochujang to fermented sausages may be an alternative way to eliminate or reduce the level of nitrate.

\section{Effect on texture}

Table 4 presents the texture profiles of fermented sausages in different treatments. It was observed that that the addition of seasonings did not affect the texture parameters such as cohesiveness, gumminess and chewiness $(p>0.05)$. Only the fermented sausages made with GMP had significantly $(\mathrm{p}<0.05)$ lower hardness value as compared to that of the control. These results suggest that the incorporation of seasonings did not cause a texture defect in the product.

\section{Effect on cholesterol, monosaccharide and sodium contents}

Table 5 presents the cholesterol, monosaccharide and sodium contents of fermented sausages made with/without test seasonings. The outcome of our analysis showed that the addition of the seasonings had beneficial effects on reduction of cholesterol content in fermented sausages. Particularly, the addition of doenjang or GMP, GHP and garlic resulted in reduction of $26.50,32.54,47.04$, and $48.54 \mathrm{mg}$ cholesterol/100 g samples, respectively as compared with that of the control $(p<0.05)$. As previously mentioned in the introduction section, fermented sausages also have some negative aspects such as the high cholesterol level which is a main cause of cardiovascular disorder disease, high blood pressure and mortality. When compared to the cholesterol levels ( $110.5 \mathrm{mg} / 100 \mathrm{~g}$ sample) reported for fermented sausages in literature (Muguerza et al., 2001), all of the fermented sausages made with seasonings in the present study had lower levels, whereas those made without the test seasonings (control) had similar or higher level. Additionally, studies with human subjects have shown that consumption of either soya products or garlic, soluble fiber and plant sterol esters for several months significantly reduced serum concentrations of total cholesterol, low-density lipoproteins cholesterol and triglycerides (Hermansen et al., 2003), however, the possible mechanism of cholesterol-lowering effect of plantsourced products in these studies still remains unclear. The present work, we assessed the effect of the addition of some traditional/natural seasonings on cholesterol content in meat products. Despite the exact mechanism underlying the cholesterol-reducing effect of the added seasonings remaining unknown, it is probably due to the bioactive components or enzymes originating from microorganisms present in these seasonings which degraded the cholesterol content in the product. Regarding this, Lee et al. (1997) and colleagues demonstrated that some microorganisms are

Table 5. Cholesterol, monosaccharide and sodium contents of fermented sausages as affected by the seasonings addition ${ }^{1}$

\begin{tabular}{lccc}
\hline Treatment & Total cholesterol $(\mathrm{mg} / 100 \mathrm{~g})$ & Monosaccharide $(\mathrm{g} / 100 \mathrm{~g})$ & $\mathrm{Na}(\mathrm{mg} / 100 \mathrm{~g})$ \\
\hline Control (C) & $118.66 \pm 13.45^{\mathrm{a}}$ & $0.50 \pm 0.00^{\mathrm{ab}}$ & $793.06 \pm 34.72^{\mathrm{ab}}$ \\
$1 \%$ doenjang (T1) & $92.12 \pm 5.31^{\mathrm{bc}}$ & $0.50 \pm 0.00^{\mathrm{ab}}$ & $984.18 \pm 100.06^{\mathrm{a}}$ \\
$1 \%$ gochu-jang (T2) & $104.10 \pm 5.59^{\mathrm{ab}}$ & $0.46 \pm 0.02^{\mathrm{b}}$ & $780.00 \pm 86.43^{\mathrm{ab}}$ \\
$1 \%$ ground medium-hot peppers (T3) & $86.12 \pm 6.92^{\mathrm{bc}}$ & $0.46 \pm 0.02^{\mathrm{b}}$ & $602.36 \pm 123.31^{\mathrm{b}}$ \\
$1 \%$ ground hot peppers (T4) & $71.62 \pm 7.24^{\mathrm{c}}$ & $0.52 \pm 0.02^{\mathrm{a}}$ & $875.06 \pm 67.21^{\mathrm{ab}}$ \\
$1 \%$ ground garlic (T5) & $70.12 \pm 2.70^{\mathrm{c}}$ & $0.48 \pm 0.02^{\mathrm{ab}}$ & $685.04 \pm 93.93^{\mathrm{b}}$ \\
\hline
\end{tabular}

\footnotetext{
${ }^{1}$ Data are the means \pm standard deviation.

Values with different letters ${ }^{(--c)}$ in the same column differ significantly $(\mathrm{p}<0.05)$.
} 
Table 6. Sensory characteristics of fermented sausages as affected by the seasonings addition ${ }^{1}$

\begin{tabular}{lcccc}
\hline Treatment & Aroma & Taste & Color & Acceptability \\
\hline Control (C) & $4.63 \pm 0.16^{\mathrm{c}}$ & $5.04 \pm 0.18^{\mathrm{c}}$ & $4.75 \pm 0.17^{\mathrm{b}}$ & $4.84 \pm 0.15^{\mathrm{c}}$ \\
$1 \%$ doenjang (T1) & $5.00 \pm 0.07^{\mathrm{bc}}$ & $5.46 \pm 0.08^{\mathrm{bc}}$ & $5.17 \pm 0.15^{\mathrm{ab}}$ & $5.38 \pm 0.14^{\mathrm{b}}$ \\
$1 \%$ gochu-jang (T2) & $5.00 \pm 0.24^{\mathrm{bc}}$ & $5.50 \pm 0.28^{\mathrm{bc}}$ & $5.42 \pm 0.21^{\mathrm{a}}$ & $5.25 \pm 0.31^{\mathrm{bc}}$ \\
$1 \%$ ground medium-hot peppers (T3) & $5.34 \pm 0.12^{\mathrm{ab}}$ & $5.59 \pm 0.05^{\mathrm{b}}$ & $4.92 \pm 0.05^{\mathrm{b}}$ & $5.37 \pm 0.04^{\mathrm{bc}}$ \\
$1 \%$ ground hot peppers (T4) & $5.30 \pm 0.13^{\mathrm{ab}}$ & $5.38 \pm 0.14^{\mathrm{b}}$ & $5.38 \pm 0.08^{\mathrm{a}}$ & $5.46 \pm 0.16^{\mathrm{ab}}$ \\
$1 \%$ ground garlic (T5) & $5.71 \pm 0.25^{\mathrm{a}}$ & $6.13 \pm 0.08^{\mathrm{a}}$ & $5.42 \pm 0.11^{\mathrm{a}}$ & $5.96 \pm 0.14^{\mathrm{a}}$ \\
\hline
\end{tabular}

${ }^{1}$ Data are the means \pm standard deviation.

Values with different letters $\left.{ }^{\mathrm{a}-\mathrm{c}}\right)$ in the same column differ significantly $(\mathrm{p}<0.05)$.

capable of degrading cholesterol or $\beta$-sitosterol. From the results/observations of our investigation it could be concluded that the addition of natural/traditional seasonings to the conventional processing formulations have powerful effects on reduction of cholesterol content in fermented sausages.

For the monosaccharide and sodium contents, the results showed that no significant differences in their levels occurred between the treatment and control samples $(\mathrm{p}>0.05)$.

\section{Effect on sensory traits}

The effect of the addition of seasonings on the sensory traits of fermented sausages is shown in Table 6. In general, incorporating the seasonings had positive effects on improvement of sensory quality of the products; however, the effects differed depending on type of seasonings added and sensory traits evaluated. In particular, the fermented sausages made with either GMP or GHP and garlic had significantly $(p<0.05)$ higher aroma and taste scores compared with that of the control. The rest of treatments with doenjang or gochu-jang also produced higher aroma and taste scores compared with that of the control but not significantly different $(\mathrm{p}>0.05)$. The reason the panelists gave higher taste and aroma scores for the fermented sausages made with the seasonings could be due to the contribution of the flavor enhancers and taste active compounds that exist within these seasonings. Additionally, the seasonings, especially chili peppers and garlic, have widely been used to enhance the flavor of many dishes for centuries due to their abundance and inexpensiveness. In meat industry, some of these ingredients are also used in meat products (Deda et al., 2007; Lorenzo et al., 2013), however, most of them are added to the meat products in the form of dry powder which has undergone a processing treatment that reduces their typical flavors. Similarly, all treatments (excepted for the case of doenjang) showed significantly higher color scores compared to that of the control. Overall acceptance is the sum of all sensory traits. Our results showed that all the treatments had generally higher acceptability scores than the control, however, statistically significant differences only were observed for the cases of doenjang, GMP and garlic treatments. The higher acceptability scores given by the panelists for these treated samples could be associated with the synergistic effect of their higher aroma, taste and color scores. Similarly, previous studies have also showed that the addition of natural ingredients (e.g., mushroom, tomato paste) had positive effects on the sensory quality of sausages (Dade et al., 2007; Seong et al., 2015). Hence our results suggest that there is the potential for these natural seasonings to improve the sensory quality of meat products in general and fermented sausages in particular.

In conclusion, the present work, for the first time assessed the impacts of addition of some traditional seasonings on the technological quality, cholesterol and sensory characteristics of fermented sausages. The addition of seasonings did not cause color or texture defects whereas they had beneficial effects on $\mathrm{pH}$ and lipid oxidation reductions in the final products. Noticeably, the addition of seasonings such as doenjang, medium-hot peppers, hot peppers and garlic significantly reduced the total cholesterol content in the products. Futhermore, the addition of these seasonings also had positive effects on improving sensory quality such as aroma, taste color and acceptability scores of the fermented sausages. Based on the results obtained in the present study it is clearly suggested that the test seasonings could be added as functional ingredients for reducing cholesterol content and improving lipid oxidation stability as well as sensory quality of fermented sausages.

\section{CONFLICT OF INTEREST}

We certify that there is no conflict of interest with any financial organization regarding the material discussed in the manuscript.

\section{ACKNOWLEDGMENTS}

This work was supported by "Cooperative Research Program for Agriculture Science \& Technology Development (Project No. PJ906974)" Rural Development Administration, Republic of Korea. 


\section{REFERENCES}

AOAC. 2000. Official Methods of Analysis of the AOAC 17th edn. Multi-Element Method, Arlington, VA, USA.

Botterweck, A. A. M., H. Verhagen, R. A. Goldbohm, J. Kleinjans, and P. A. van den Brandt. 2000. Intake of butylated hydroxyanisole and butylated hydroxytoluene and stomach cancer risk: Results from analyses in the Netherlands cohort study. Food Chem. Toxicol. 38:599-605.

Cha, Y. S., Y. Park, M. Lee, S. W. Chae, K. Park, Y. Kim, and H. S Lee. 2014. Doenjang, a Korean fermented soy food, exerts antiobesity and antioxidative activities in overweight subjects with the PPAR-c2 C1431T polymorphism: 12-Week, doubleblind randomized clinical trial. J. Med. Food 17:119-127.

Chaves-López, C., A. Serio, G. Mazzarrino, M. Martuscelli, E. Scarpone, and A. Paparella. 2015. Control of household mycoflora in fermented sausages using phenolic fractions from olive mill wastewaters. Int. J. Food Microbiol. 207:49-56.

Chow, C. K. and C. B. Hong. 2002. Dietary Vitamin E and selenium and toxicity of nitrite and nitrate. Toxicology 180:195-207.

Chung, L. Y. 2006. The antioxidant properties of garlic compounds: Allyl cysteine, alliin, allicin, and allyl disulfide. J. Med. Food 9:205-213.

Corral, S., A. Salvador, C. Belloch, and M. Flores. 2014. Effect of fat and salt reduction on the sensory quality of slow fermented sausages inoculated with Debaryomyces hansenii yeast. Food Control 45:1-7.

Deda, M. S., J. G. Bloukas, and G. A. Fista. 2007. Effect of tomato paste and nitrite level on processing and quality characteristics of frankfurters. Meat Sci. 76:501-508.

Frenandez-Salguero, J., R. Gomez, and M. A. Carmona. 1993. Water activity in selected high moisture foods. J. Food Compsost. Anal. 6:364-369.

Hermansen, K., B. Dinesen, L. H. Hoie, E. Morgenstern, and J. Gruenwald. 2003. Effects of soy and other natural products on LDL:HDL ratio and other lipid parameters: A literature review. Adv. Ther. 20:50-78.

Honikel, K. O. 2008. The use and control of nitrate and nitrite for the processing of meat products. Meat Sci. 78:68-76.

Kim, J. I., J. C. Kim, M. J. Kang, M. S. Lee, J. J. Kim, and I. J. Cha. 2005. Effects of pinitol isolated from soybeans on glycemic control and cardiovascular risk factors in Korean patients with type II diabetes mellitus: a randomized controlled study. Eur. J. Clin. Nutr. 59:456-458.

Kim, Y. J., S. Y. Park, H. C. Lee, S. S. Yoo, S. J. Oh, H. S. Kim, and K. B. Chin. 2014. Evaluation of fermented sausages manufactured with reduced-fat and functional starter cultures on physicochemical, functional and flavor characteristics. Korean J. Food Sci. Anim. Resour. 34:346-354.

Kurćubić, V. S., P. Z. Mašković, J. M. Vujić, D. V. Vranić, S. M. Vesković-Moračanin, D. G. Okanović, and S. V. Lilić. 2014. Antioxidant and antimicrobial activity of Kitaibelia vitifolia extract as alternative to the added nitrite in fermented dry sausage. Meat Sci. 97:459-467.
Kwon, D. Y., K. R. Chung, H. J. Yang, and D. J. Jang. 2015. Gochu-jang (Korean red pepper paste): A Korean ethnic sauce, its role and history. J. Ethn. Foods 2:29-35.

Lee, M. T., W. C. Chen, and C. C. Chou. 1997. Nutritional factors that affect the production of cholesterol oxidase by Rhodococcus equi no. 23. Biotechnol. Appl. Biochem. 26:159162

Lorenzo, J. M., R. M. González-Rodríguez, M. Sánchez, I. R. Amado, and D. Franco. 2013. Effects of natural (grape seed and chestnut extract) and synthetic antioxidants (buthylatedhydroxytoluene, BHT) on the physical, chemical, microbiological and sensory characteristics of dry cured sausage "chorizo. Food Res. Int. 54:611-620.

Materska, M. and I. Perucka. 2005. Antioxidant activity of the main phenolic compounds isolated from hot pepper fruit (Capsicum annuum L).J. Agric. Food Chem. 53:1750-1756.

Meilgaard, M., G. V. Civille, and B. T. Carr. 1991. Sensory Evaluation Techniques 4th edn. CRC Press, Boca Raton, FL, USA.

MFDA. 2014. General Analysis Methods of the Ministry of Food and Drug Safety of Korea. 9th edn. Cheongju, Korea.

Muguerza, E., O. Gimeno, D. Ansorena, J. G. Bloukas, and I. Astiasaran. 2001. Effect of replacing pork back-fat with preemulsified olive oil on lipid fraction and sensory quality of Chorizo de Pamplona -a traditional Spanish fermented sausage. Meat Sci. 59:251-258

Nassua, R. T., L. A. G. Goncalves, M. A. A. P. da Silva, and F. J. Beserra. 2003. Oxidative stability of fermented goat meat sausage with different levels of natural antioxidant. Meat Sci. 63:43-49.

Ozvural, E. B. and H. Vural. 2011. Grape seed flour is a viable ingredient to improve the nutritional profile and reduce lipid oxidation of frankfurters. Meat Sci. 88:179-183.

Papadima, S. N. and J. G. Bloukas. 1999. Effect of fat level and storage conditions on quality characteristics of traditional Greek sausages. Meat Sci. 51:103-113.

Pikul, J., D. E. Leszczynski, and A. Kummerow. 1989. Evaluation of three modified TBA method for measuring lipid oxidation in chicken meat. J. Agric. Food Chem. 37:1309-1313.

Seong, P. N., K. M. Park, G. H. Kang, S. H. Cho, B. Y. Park, and H. Van-Ba. 2015. The impact of addition of shiitake on quality characteristics of frankfurter during refrigerated storage. LWT - Food Sci. Technol. 62:62-68.

Shukla, S., H. K. Park, J. S. Lee, J. K. Kim, and M. Kim. 2014. Reduction of biogenic amines and aflatoxins in Doenjang samples fermented with various Meju as starter cultures. Food Control 42:181-187.

Yim, D. G., K. H. Jang, and K. Y. Chung. 2015. Effect of GdL addition on physico-chemical properties of fermented sausages during ripening. Korean J. Food Sci. Anim. Resour. 35:322329 .

Zanardi, E., S. Ghidini, A. Battaglia, and R. Chizzolini. 2004. Lipolysis and lipid oxidation in fermented sausages depending on different processing conditions and different antioxidants. Meat Sci. 66:415-423.

Zapelena, M. J., I. Astiasaran, and J. Bello. 1999. Dry fermented sausages made with a protease from Aspergillus oryzae and/or a starter culture. Meat Sci. 52:403-409. 